\title{
GIS-based regression modeling of the extreme weather patterns in Arkansas, USA
}

Kyle W. Rowden and Mohamed H. Aly

\begin{abstract}
Background: Investigating the extreme weather patterns (EWP) in Arkansas can help policy makers and the Arkansas Department of Emergency Management in establishing polices and making informed decisions regarding hazard mitigation. Previous studies have posed a question whether local topography and landcover control EWP in Arkansas. Therefore, the main aim of this study is to characterize factors influencing EWP in a Geographic Information System (GIS) and provide a statistically justifiable means for improving building codes and establishing public storm shelters in disaster-prone areas in the State of Arkansas. The extreme weather events including tornadoes, derechos, and hail that have occurred during 1955-2015 are considered in this study.

Results: Our GIS-based regression analysis provides statistically robust indications that explanatory variables (elevation, topographic protection, landcover, time of day, month, and mobile homes) strongly influence EWP in Arkansas, with the caveat that hazardous weather frequency is congruent to magnitude.

Conclusions: Results indicate a crucial need for raising standards of building codes in high severity regions in Arkansas. Topography and landcover are directly influencing EWP, consequently they make future events a question of "when" not "where" they will reoccur.
\end{abstract}

Keywords: Extreme weather, GIS, Regression modeling, Risk assessment, Arkansas

\section{Background}

Arkansas is located in the Southcentral Heartland of the United States of America (Fig. 1) and ranks 4th and 5th in the USA for tornado-related fatalities and injuries, respectively. From 1955 to 2015, there have been 306 fatalities and over 4800 injuries related to severe weather in Arkansas (FEMA 2008). Although no precise definition exists for what is colloquially referred to as "Tornado Alley", the Federal Emergency Management Agency (FEMA) insets Arkansas in the center of the highest frequency region of the USA for high wind events (tornadoes and derechos), as shown in Fig. 1. Hail, which can range in magnitude from pea-size to grapefruit size (NOAA, 2017a, 2017b) has been considered with these wind events. Such geoenvironmental weather-related hazards will continue to reoccur, thus it is fundamental to investigate their spatial and temporal patterns to advance understanding of their reoccurrence and to minimize human and environmental vulnerability.

\footnotetext{
* Correspondence: dr.m.aly@gmail.com

Department of Geosciences, University of Arkansas, Fayetteville 72701, Arkansas, USA
}

Spatio-temporal analysis of the extreme weather patterns (EWP) has been exhaustedly conducted for other states (e.g. Bosart et al. 2006; Gaffin 2012: Lewellen 2012; Lyza and Knupp 2013); but until recently very limited analysis, focused on just storm severity of individual events and topography, has been conducted over Arkansas (e.g. Selvam et al. 2014, 2015; Ahmed and Selvam 2015a, 2015b, 2015c; Ahmed 2016). A three-dimensional overview of Arkansas' topography and weather patterns related to predominant wind directions elucidates a preference for these prevailing winds to funnel hazardous weather into concentrated zones along the eastern front of the Ouachita and Boston Mountains as well as through the Arkansas River Valley (Fig. 2). Unfortunately, the severe weather tracks are mainly concentrated in the highest populated areas in Arkansas.

A common misconception propagates an axiom through rural communities that tornadoes do not occur in mountainous terrains, but this is just a myth (Lyza and Knupp 2013). Fujita (1971) first observed that tornadoes have a tendency to strengthen on the down-slope of their storm track. More researchers have followed Fujita's footprints pursuing the relationship between topography and severe 


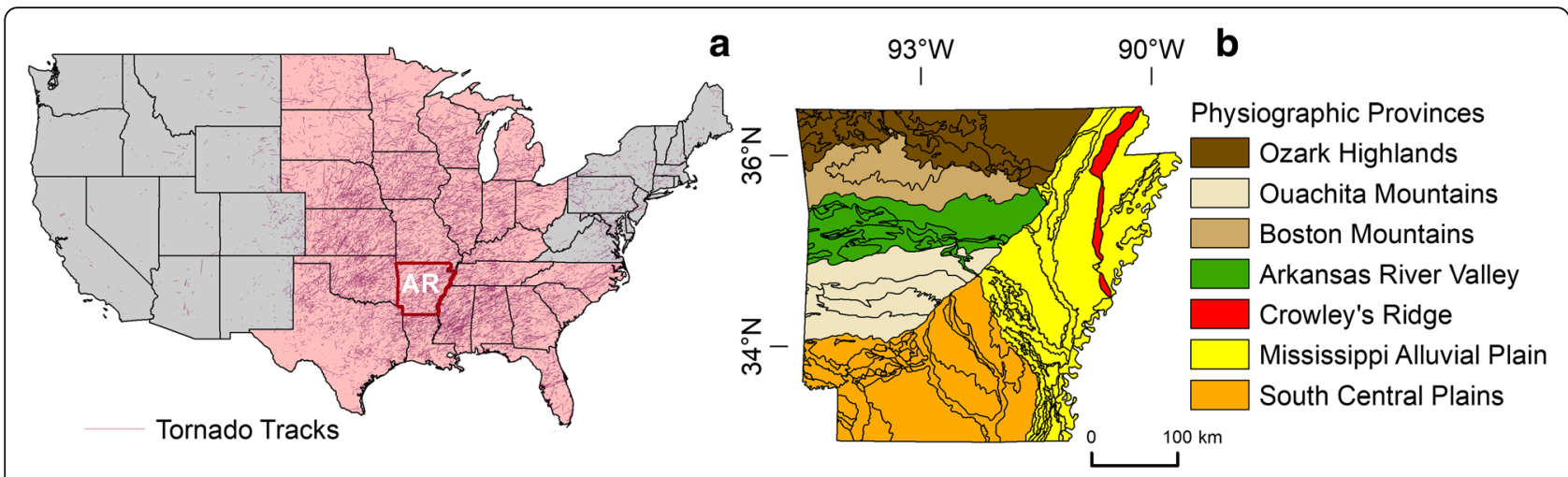

Fig. 1 a Light red region indicates the highest frequency of tornadoes in the United States of America. AR denotes the State of Arkansas. b Physiographic provinces of Arkansas that have topographic and land surface features influencing severe weather patterns

weather events (e.g. LaPenta et al. 2005; Bosart et al. 2006; Frame and Markowski 2006; Markowski and Dotzek 2011; Gaffin 2012; Karstens et al. 2013; Lyza and Knupp 2013). Forbes et al. (1998) and Forbes \& Bluestein (2001) provided more insightful observations: (1) widths of destructive swaths contract on down slopes, (2) intense swirls are most likely occurring at the base of mountains or along the down slope path, (3) intensity of a tornado is likely to decrease on the upward slope, and (4) tornadoes are likely to weaken on a jump from one hill top to another and strengthen upon touching down on the adjacent hill. Lewellen (2012) elaborated on these observations and questioned whether topography might statistically provide zones of safety from severe weather. Other explanatory variables (EV) influencing damage include concentrations of mobile homes, often referred to as "trailer parks". Kellner and Niyogi (2013) examined the phenomenon of tornado attraction to mobile home communities and determined that these communities do not attract strong weather events as much as these communities are constructed in the undesirable hinterlands that are heavily prone to severe weather patterns.

Severe weather will continue to strike Arkansas as well as the rest of the world. As this is unavoidable, then the main concern is how patterns of extreme weather can be used to promote effective disaster mitigation efforts. Crichton (1999) defines risk as the probability loss that may occur based on three components (Fig. 3): (1) hazards, (2) vulnerability, and (3) exposure. The specific objective of this study is to investigate spatial and temporal patterns associated with extreme weather phenomena (tornadoes, derechos, and hail) at the state level from 1955 to 2015 by standardizing and constraining all documented weather events to a $10 \times 10-\mathrm{km}$ grid. Grid standardization provides a systematic approach to examine subsets of severity, including frequency and magnitude, via extrapolating statistics related to fatalities, injuries, and property loss. Geostatistical analysis utilizing Ordinary Least Squares (OLS) regression is powerful in determining the most disaster-prone areas in Arkansas, and results support

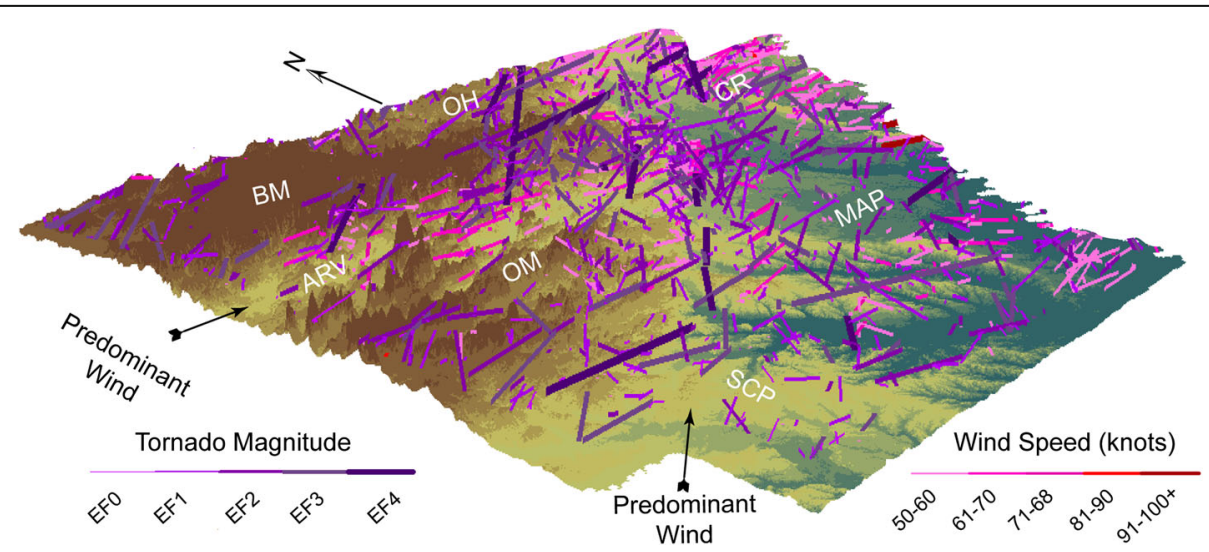

Fig. 2 Prevalent wind directions (southwesterly and westerly) and the related weather patterns (1 knot =1.852 km/h or $1 \mathrm{nautical}$ mile/h). Arkansas Physiographic provinces are indicated as: Ozark Highlands (OH), Ouachita Mountains (OM), Boston Mountains (BM), Arkansas River Valley (ARV), Crowley's Ridge (CR), Mississippi Alluvial Plain (MAP), and South Central Plain (SCP) 


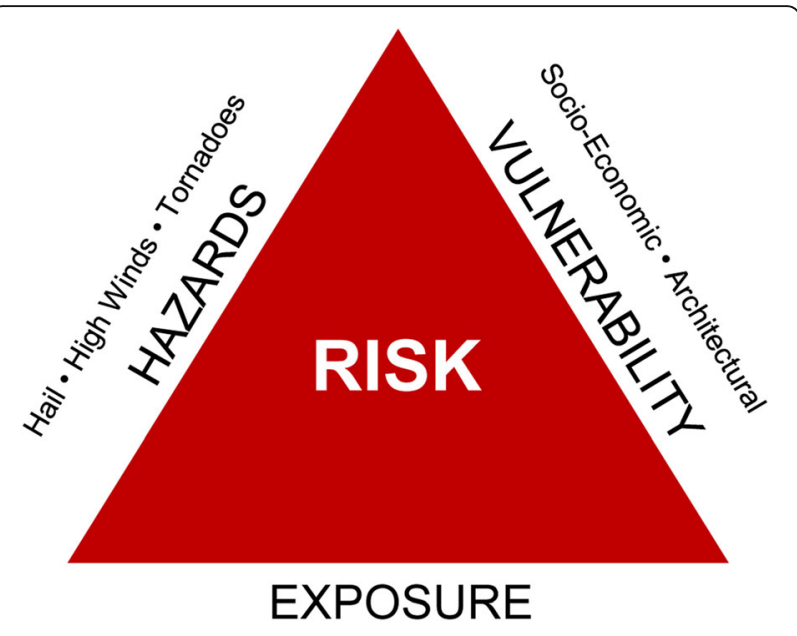

Commerce $\cdot$ Lives $\cdot$ Structures

Fig. 3 The risk hazard triangle (adapted from Chrichton 1999). Hazards pose no risk if there is not some amount of exposure and vulnerability

initiatives to improve building codes in high risk areas (e.g. FEMA 2008; Safeguard 2009). This research will definitely improve awareness of potential hazards related to extreme weather and will help the policy makers in making informed decisions with regard to public storm shelters across Arkansas. Moreover, the developed GIS procedure can be replicated to investigate the spatio-temporal patterns of severe weather in other locations across the world.

\section{Study area}

Along with tornadoes, Arkansas is prone to powerful supercell thunderstorms that can produce large magnitude hail storms and deadlier derechos (also known as "straight-line winds" or "micro-bursts"), which are strong wind events with gusts exceeding 50 knots. Historically, the highest injury and fatality counts related to severe weather in Arkansas and the rest of USA predate the 1950's when the first weather forecasting station was installed at Tinker Air Force Base in Oklahoma, coinciding with President Harry Truman's signing of the Civil Defense Act (CDA) in 1950 (Galway 1985; Bradford 1999 1;2001; Coleman et al. 2011). The CDA mandated installation of warning sirens across the USA, which became the saving grace for countless Americans from severe weather strikes.

Although the National Weather Service (NWS) issues weather forecasts, severe weather warnings come out of the local offices (located in Little Rock in the case of Arkansas) and the Storm Prediction Center (SPC) releases severe storm watches (Edwards 2017). Early detection and warning are important factors reducing exposure to severe weather, but still the contemporary technology cannot predict weather with $100 \%$ accuracy. The National Climatic Data Center (NCDC), part of the National Oceanic and
Atmospheric Administration (NOAA), has recorded 1681 tornadoes from 1955 to 2015 (National Climatic Data Center 2013; NOAA 2017a, 2017b). Figure 4 tragically shows fatalities and injuries suffered by Arkansas during the time frames examined in this study.

Arkansas has three main population centers located in unique regions across the state. These being the Little Rock metropolitan area that includes Little Rock, Jacksonville, Cabot, Benton, Maumelle, and Conway located in the geographic center of the state; northwest Arkansas (NWA) which includes Fayetteville, Springdale, Rodgers, and Bentonville; and lastly Jonesboro in northeastern Arkansas. All these regions are vital socio-economic hubs for the state and the USA and unfortunately are prone to the most violent episodes of hazardous weather.

The city of Little Rock (Pulaski County) houses the State Capital along with all major state agency headquarters as well as large private sector corporations such as Dillard's, a fortune 500 company headquartered in Little Rock (Fortune 2017). Little Rock's population is 200,000 people. When taking into consideration the counties adjacent to Pulaski County, there are over 700,000 residents with even more working in this region daily (U.S. Census 2016). Central Arkansas is consistently hit with the highest frequency and magnitude events annually. For an instance, on April 27, 2014, the Mayflower Tornado touched down about $25 \mathrm{~km}$ northwest of Little Rock carving a 70-km path of destruction. This tornado remained on the ground for over $60 \mathrm{~min}$, reaching a maximum width of $\sim 1 \mathrm{~km}$, killed 16 lives and injured over 120 people. This was the second deadliest single tornadic event in Arkansas in the past 50 years.

NWA is the second most populated area in the state with the two counties (Benton and Washington) having a combined total of 500,000 residents (U.S. Census 2016). The University of Arkansas located in Fayetteville is the largest university in the state with a current enrollment of $\sim 28,000$ students in fall of 2017 (UA 2017). Multiple fortune 500 companies are headquartered in NWA, these being Walmart (\#1 biggest company in the world), Tyson Foods, J.B. Hunt Transportation (Fortune 2017) along with the ancillary business these companies drawn in. Walmart, and its related U.S. distribution, is anchored in Arkansas with 6 of Arkansas' 10 distribution centers, supporting the billion-dollar corporation being located in NWA. Although not immediately in Arkansas, the May 22, 2011, EF-5 Joplin Tornado was one of the most powerful and deadliest tornadoes in U.S. history and was responsible for 158 fatalities, over 1150 injuries, and $\$ 2.8$ billion dollars' worth of damage (Kuligowski et al. 2014). It is conceivable that a tornado of this magnitude could strike NWA.

Lastly, Jonesboro, the county seat for Craighead County has a population of more than 100,000 residents and 


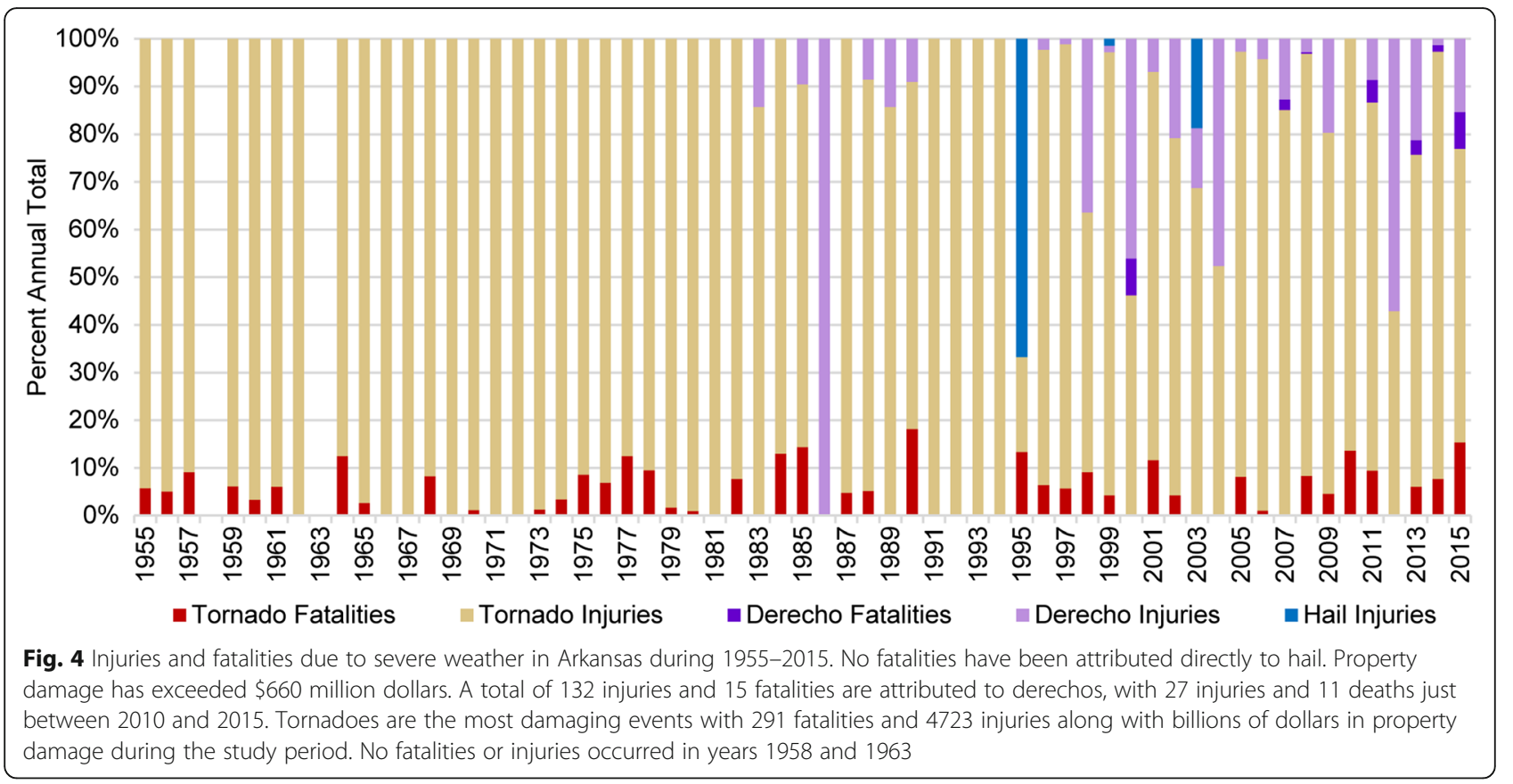

supports the second largest university in the state; Arkansas State University with 25,000+ enrollments (ASU website 2017). Although this region of Arkansas doesn't have the quantity of people as the aforementioned regions, Jonesboro serves as the agricultural center for Arkansas as well as much of the USA. Arkansas is the number- 1 rice producing state in the USA by raising more than $50 \%$ of domestic rice. Billion dollars agriculture companies, such as Riceland Foods, Inc., operate out of this region and export more than $60 \%$ of Arkansas rice (ARFB 2017) to the international market.

The Mississippi Alluvial Plain (MAP) often referred to as the Arkansas Delta is a flat lowland physiographic region nearly void of any topographic relief apart from Crowley's Ridge just west of Jonesboro. This type of landscape is particularly favorable for agriculture but meanwhile it is also proper for broad sweeping weather patterns with the capability of inundating the region with heavily rains. For instance, a hail event occurred in May 2015 in close proximity to Walnut Ridge (45 km northwest of Jonesboro) produced hail up to 5 in. in diameter. Hail of this size is large enough to kill people and livestock, as well as destroy roofs of houses. Fortunately, this event missed a direct hit on Walnut Ridge and occurred across the agricultural land adjacent to the town. Derechos frequently strike this region accounting for $30 \%$ of all derechos in the state. Single microburst can cause millions of dollars in damage such as the event on May 12 of 1990 that was responsible for $\$ 6$ million dollar in property loss. Derechos' magnitudes may exceed 100 knots, such as the recent event on January 22, 2012. The same weather system also spawned 7 tornadoes and blanketed the MAP region with hail up to 3 in., emphasizing the interconnectedness of all three severeweather types within a single storm. Event details and weather-related statistics are extracted from the GIS metadata that are publicly available through NOAA and NWS geodata as part of the Storm Prediction Center's Severe GIS (SVRGIS) data repository.

\section{Methods}

GIS is employed to categorize and compartmentalize unique attributes from datasets into equal interval $10 \times$ $10 \mathrm{~km}$ grids for the entire state. Grid analysis provides a higher level of specificity to weather patterns compared to the broad, low precision county level analysis previously conducted by multiple governmental and state agencies (e.g. FEMA 2002, 2008; NCDC 2013). The complete process along with the conducted regression analysis steps are demonstrated in the flowchart shown in Fig. 5 and are explained below.

\section{Gridding and standardizing input data}

Fishnetting allows storm tracts to be standardized into grids, supporting field summing, as well as later analysis of original attributes. Grid size is standardized to $10 \times 10 \mathrm{~km}$ in this study. A 1-arc sec digital elevation model (DEM) for the state is classified into ten classes using an interval of $82.66 \mathrm{~m}$ that closely mirrored a stretch classification method. These respective elevation attributes are then joined to the $10 \times 10 \mathrm{~km}$ grid. Primary alchemy applied to this analysis revolves around the spatial join tool available in ArcGIS release 5.10.1, presenting two valuable options: (1) one-to-one, where a 1:1 ratio is maintained and the choice to sum totals is used to get sums of attributes 


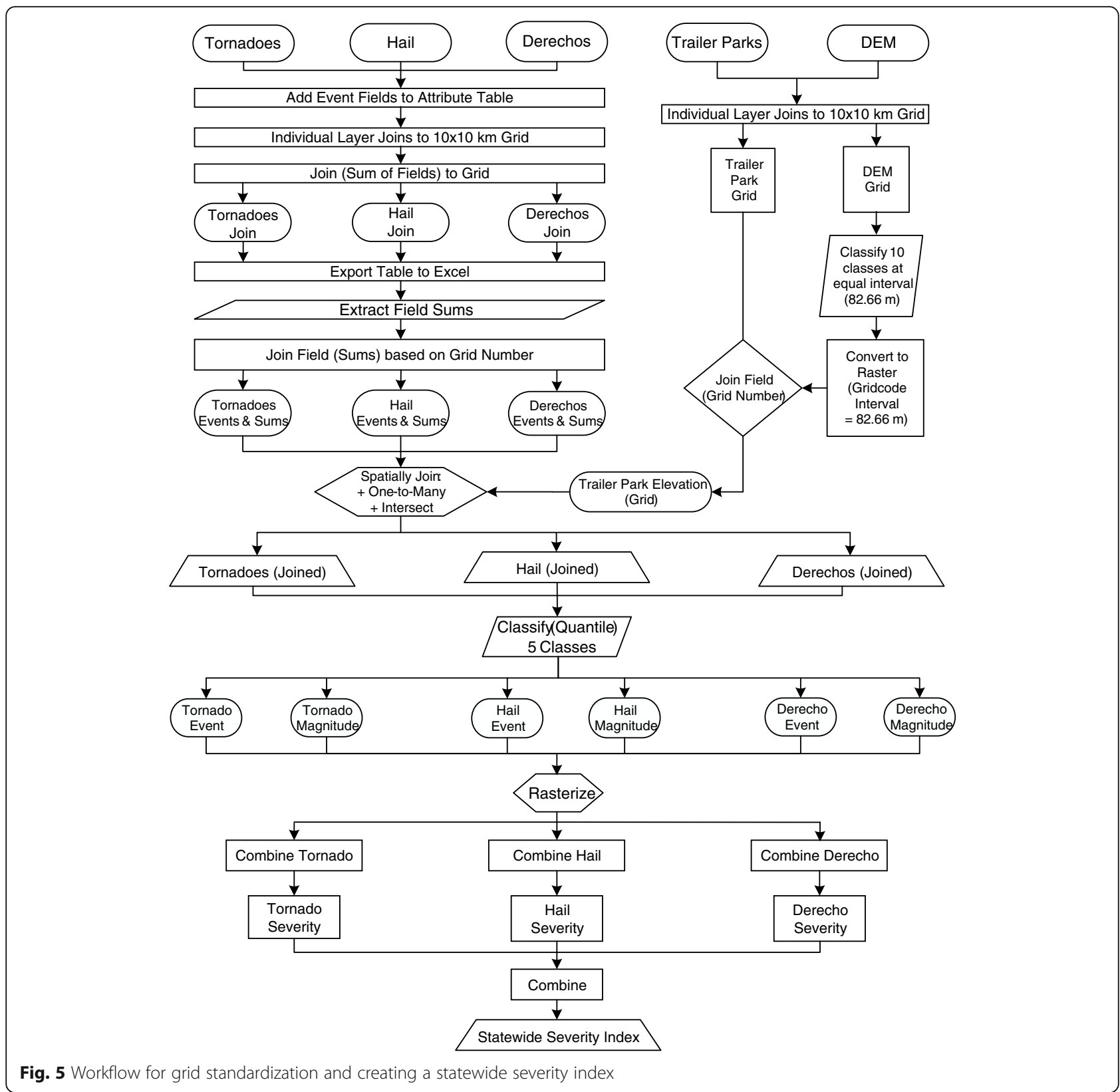

for each respective cell and (2) one-to-many, which allows user selected attributes from a line, representing a storm track, intersecting multiple grid cell to be added. The oneto-many spatial join has been used in this study to model event frequencies for each respective weather hazard.

\section{Creating severity indices}

Initially, event frequency and magnitude vectors are converted into raster, where the cell values of each respective variable become a grid code output, then the frequency and magnitude are combined for each weather event. Later, a severity index is established for each respective weather event, with each component of the triad being combined into a final statewide severity index using this simple formula:

$$
S S I=T S \times D S \times H S
$$

where SSI is the statewide severity index, TS is the tornado severity, $D S$ is the derecho severity, and $H S$ is the hail severity.

\section{Exploratory regression}

Regression analyses provide a means for exploratory data trends, offering statistical scrutiny of influential spatiopatterns. The exploratory regression (ER) tool in ArcGIS 
(5.10.1) provides a simplistic means for trial and error experimentation, allowing the analyst a to narrow down factors that may be influencing the dependent variable model. ER is employed in this study as a first step investigation to conduct an OLS regression on the most influential variables. Explanatory variables (EV) considered in this analysis are found to be: trailer parks, elevation, topographic protection, physiographic ecological sub regions. These variables are chosen based on results from previous studies (e.g. LaPenta et al. 2005; Bosart et al. 2006; Frame and Markowski 2006; Markowski and Dotzek 2011; Gaffin 2012; Karstens et al. 2013; Lyza and Knupp 2013) that show strong correlations between topography, elevation, land cover features, and windward aspects of topographic features to directly influence strength and subsequent severity of weather events. Several statistical properties are used to determine the strength of EV.

The coefficient of determination referred to as Adjusted $R^{2}$ and evaluated by Steel and Torries (1960) as:

$$
R_{a d j}^{2}=1-\left[\frac{\frac{\text { SSError }}{(n-k)}}{\frac{\text { SSTotal }}{n-1}}\right]
$$

where $\mathrm{R}$ is the coefficient for multiple regressions, $k$, denotes the quantity of coefficients implemented in the regression, $n$, the number of variables, SSError, the sum for standard error and SSTotal is the total sum of squares.

The statistical $t$-test developed by Gosset (1908) can be simplified as:

$$
t=\frac{Z}{s}=\frac{(\bar{X}-\mu)\left(\frac{\sigma}{\sqrt{n}}\right)}{s}
$$

where $\bar{X}$ is representative of the sample's mean where the sample ranges from $X_{1}, X_{2}, \ldots . X_{n}$, out of a size $n$, which follows a natural tendency of normal distribution between the variance in $\sigma^{2}$ and $\mu$, with $\mu$ denoting mean population, and $\sigma$ being the standard deviation in the population.

Koenker (BP) statistic that is a chi-squared test for heteroscedasticity, originally developed by Breusch and Pagan (1979) and later adapted to by Koenker (1981), is expressed as:

$$
L M=\frac{1}{2}\left[\frac{N}{n(N-n)}\right]\left[\sum_{t}^{n}\left(\frac{\hat{u}_{t}^{2}}{\hat{\sigma}^{2}}\right)-n\right]^{2}
$$

in which $L M$ is a Lagrange Multiplier, $N$ denotes the number of observations, $\mathrm{n}$ the sample size, $\hat{u}_{t}^{2}$ are the dependent gamma residuals, $\hat{\sigma}^{2}$ is the estimated residual variance in observations.

Akaike's Information Criterion correction (AICc) is used to estimate relative quality for a given statistical model and is based on information theory and serves as a means of ranking the quality of multiple to models with respects to one another. AICc is based on Akaike Information Criterion (AIC) (Akaike 1973, 1974; 2010) and corrects for a finite sample size:

$$
A I C c=A I C+\frac{2 k(k+1)}{n-k-1}
$$

with $k$ denoting the number of parameters and $n$, the sample size (e.g. Burnham and Anderson 2002; Konishi and Kitagawa 2008).

The Jarque-Bera statistical test is used to check for data sample skewness and kurtosis match on a normal distribution curve through:

$$
J B=\frac{n-k+1}{6}\left(S^{2}+\frac{1}{4}(C-3)^{2}\right)
$$

in which $S$ is skewness in the dataset, $C$ is the sample's kurtosis, $n$ the number of observations, and $k$ represents the quantity regressors (e.g. Jarque and Bera 1980, 1981; and 1987).

The reciprocal of tolerance (also known as the maximum Variance Inflation Factor - VIF) (Belsley et al. 1980; Belsley 1984; O'brien 2007) can be expressed as:

$$
V I C=\left(\frac{1}{\left(1-R_{i}^{2}\right)}\right)
$$

where tolerance of the $i$ th variable is 1 less, the proportion of variance which is $R_{i}^{2}$ (O'brien 2007).

The Spatial Autocorrelation (SA) essentially draws on a Global Moran's I value based on Tobler's (1970) Law to calculate p-scores and z-scores. P-scores designate probability percentages that range from 0.10 to $<0.01$ (weak), null, and 0.10 to $<0.01$ (strong). Z-scores represent standard deviations, when combined with a strong corresponding p-scores indicate robust confidence. Ranges for Zscores are $($ weak) $<-2.58$ up to (strong) $>2.58$. Moran's $I$ is defined by ESRI (2016) as:

$$
I=\frac{n \sum_{i=1}^{n} \sum_{j=1}^{n} W_{i}, j z_{i} z_{j}}{S_{0} \sum_{i=1}^{n} z_{i}^{2}},
$$

where deviation of an attribute's feature, $I$, from mean $\left(x_{i}-X\right)$ is $z_{i}, n$ denotes total feature count, spatial weighting between $(i, j)$ becomes $W_{i}, j$, and lastly the amalgamation of these spatial weights is $S_{0}$ :

$$
S_{0}=\sum_{i=1}^{n} \sum_{j=1}^{n} W_{i}, j
$$

$\mathrm{Z}_{\mathrm{I}}$-scores are calculated with: 


$$
z_{I}=\frac{I-E[I]}{\sqrt{V[I]}}
$$

where:

$$
\begin{aligned}
& E[I]=-\frac{1}{n-1}, \\
& V[I] a=E\left[I^{2}\right]-E\left[I^{2}\right],
\end{aligned}
$$

\section{Ordinary least squares}

OLS is perhaps the most commonly used forms of regression analysis in GIS. Amemiya (1985) defines it as:

$$
y=\beta_{0}+\beta_{1} X_{1}+\beta_{2} X_{2}+\beta_{3} X_{3}+\cdots \cdots \beta_{n} X_{n}+\epsilon
$$

where $y$ is the dependent variable which is the variable that is predicting or explaining the model and is a function of $X$, which are coefficients representing EVs that, together, help answer $y . \beta$ are regression coefficients that are calculated through algorithms running in the GIS background and $\beta_{O}$ is the regression intercept and represents an expected outcome for $y$ and $\varepsilon$ are the residual random error terms.

As part of the OLS process, we run a SA utilizing Global Moran's I, which determines the likeliness of randomly chosen EVs relative to their spatial distribution and impact. Other statistical outputs included in the final OLS include: (1) StdError and (2) Robust ${ }_{S E}$, which are errors in standard deviation; (3) t-Statistic and (4) Robust $t_{t}$ which are ratios between an estimated value of a parameter and a hypothesized value relative to standard error; (Akaike, 1973) probability and (Akaike, 1974) robust probability $\left.{ }_{(P r}\right)$, which are the statistically significant coefficients $(p<0.01)$; should initial probability values possess a significant (Akaike, 2011) Koenker statistic, then (pr) is used to determine significance of coefficient; (Arkansas Farm Bureau, 2017) VIF factors (> 7.5) that are indicative of redundancy; (Arkansas State University, 2016) Joint Wald statistic, which help determine model's overall significance if Koenker value is significant; and finally (Amemiya, 1985) AICc and (Belsley et al., 1980) $R^{2}$, which are measures of model's overall fit and performance.

\section{Quantile classification}

Quantile classification is used for the symbology of all choropleth maps. Quantile is chosen as the appropriate means for classification because it creates classes based on equal division of units in each class (e.g. Cromley 1996; Brewer and Pickle 2002; Burnham and Anderson 2002; Xiao et al. 2007, Sun et al. 2015). Quantile classification most closely represents the input data trends that are poorly represented using other classification methods, such as Jenks-Natural breaks, equal interval, standard deviation, and geometric classifications.

\section{Results and discussion}

Patterns with strong positive correlations are detected between the frequency of severe weather events and time of day, elevation, and magnitude (Tables 1, 2 and 3). Primary patterns are explored in the preliminary determination of EV used in the exploratory regression. The three types of hazards showed a strong tendency to occur between 2:00 and 10:00 pm (Tables 1, 2 and 3). This is a noteworthy observation because Arkansas becomes dark around 5:30 pm in fall and winter months, reducing the visual line-of-sight to nearly null and limiting rural residents visual warning detection. A second pattern is found at the elevation of $165 \mathrm{~m}$ with the highest frequency of 660 out of 1677 tornadic events $(\sim 40 \%)$ occurred during the study period. A higher frequency of hail and derecho events are found to occur at the 165-m elevation. A secondary pattern is found occurring within a narrow range between $200 \mathrm{~m}$ and $250 \mathrm{~m}$. A third pattern and the strongest positive correlation is found between frequency and magnitude, indicating a natural tendency for these weather hazards to be strong in areas of high frequency. Such areas are experiencing the highest severity and risk. A fourth pattern found is that the spatial distribution of these events occurs in the central part of Arkansas in the surrounding area of Little Rock (Figs 2 and 12). This metropolitan area has the highest population density, $\sim 350,000$ residents - this number approaches 500,000 during work days. The highest severity rankings for all weather events are centralized around Little Rock. This area also has the highest property and crop damage due to extreme weather events.

Tornadoes are, by far, the most destructive and deadliest of the three weather types considered in this research (Fig. 4). Tornadoes have posed a serious risk for Arkansans long before weather data archival began in 1950. Figure 6 highlights several geospatial patterns and illuminates the directional tendency of tornado paths to propagate in a northeastern direction. Lineaments of destruction can be followed along the eastern flanks of the Ouachita and Boston Mountains (these physiographic features are marked in Fig. 1 and Fig. 2), with property damage totaling over $\$ 300$ million dollars in individual grid cells (Fig. 6e). Crop damage is the least concern with respect to tornadoes. This being said, the majority of the highest magnitude EF-4 tornadoes has occurred in the past decade, including the April 27 of 2014 Mayflower tornado that killed 15 people and injured over 100 (Selvam et al. 2014). OLS analysis provides strong indications that the $\mathrm{EV}$ of month, time of day (TIME_ADJ), physiographic region (AR_ECO_ID), trailer parks, and topographic protection to be robust indicators in the final model, where * denotes statistical significant $p$ values in Table 1 . OLS output has \pm 2 standard deviations of residuals from best prediction indicating that EVs predict $80 \%$ of the model as determined from residual $R^{2}$ value of 0.78686. Std output shown in Fig. 7 displays a dominant \pm 1 
Table 1 Ordinary Least Squares results for tornadoes

\begin{tabular}{llllllllll}
\hline & Variable & Coefficient & StdError & t-Statistic & Probability & Robust_SE & Robust_t & Robust_Pr & VIF \\
\hline Event & Intercept & 2.9560 & 0.2807 & 10.5299 & $0.000000^{*}$ & 0.2917 & 10.1329 & $0.000000^{*}$ & - \\
& Month & 0.0279 & 0.0059 & 4.7338 & $0.000003^{*}$ & 0.0058 & 4.8383 & $0.000002^{*}$ & 1.0391 \\
& ADJ_TIME & 0.0246 & 0.0035 & 7.0107 & $0.000000^{*}$ & 0.0031 & 7.8801 & $0.000000^{*}$ & 1.1056 \\
& SUM_MAG & 0.4708 & 0.0042 & 112.0444 & $0.000000^{*}$ & 0.0049 & 96.6009 & $0.000000^{*}$ & 1.1092 \\
& AR_ECO_ID & -0.0021 & 0.0002 & -13.1645 & $0.000000^{*}$ & 0.0002 & -11.4925 & $0.000000^{*}$ & 1.0497 \\
& Protection & 0.1328 & 0.0517 & 2.5702 & $0.010193^{*}$ & 0.0403 & 3.2951 & $0.001009^{*}$ & 1.0600 \\
Magnitude & Intercept & -6.3259 & 0.5174 & -12.2254 & $0.000000^{*}$ & 0.4869 & -12.9926 & $0.0000000^{*}$ & - \\
& Month & -0.0274 & 0.0109 & -2.5071 & $0.012203^{*}$ & 0.0107 & -2.5624 & $0.010423^{*}$ & 1.0452 \\
& ADJ_TIME & 0.0096 & 0.0065 & 1.4702 & 0.141599 & 0.0057 & 1.6650 & 0.096012 & 1.1194 \\
& Event (Sum) & 1.6066 & 0.0145 & 111.0131 & $0.000000^{*}$ & 0.0173 & 92.6609 & $0.000000^{*}$ & 1.1401 \\
& Elevation & -0.0011 & 0.0004 & -3.0899 & $0.002030^{*}$ & 0.0004 & -3.0349 & $0.002434^{*}$ & 1.9239 \\
& Trailer Parks & -0.0411 & 0.0080 & -5.1587 & $0.000001^{*}$ & 0.0082 & -5.0265 & $0.000001^{*}$ & 1.1378 \\
& AR_ECO_ID & 0.0054 & 0.0004 & 15.1201 & $0.000000^{*}$ & 0.0004 & 13.6639 & $0.000000^{*}$ & 1.5146 \\
& Protection & 0.0552 & 0.1118 & 0.4935 & 0.621665 & 0.0894 & 0.6170 & 0.537257 & 1.4571 \\
& & Joint Wald & Jarque-Bera & Koenker (BP) Statistic & AlCc & Adjusted R2 & $13,317.7251$ & 0.78686 & \\
\hline
\end{tabular}

Significant $p$-values $(p<0.01)$ are denoted by *, StdError is the standard deviation error, $t$-Statistic is the ratio between estimated and hypothesized values relative to StdError, probability and robust probability $\left({ }_{P r}\right)$ are significant when $(p<0.01)$, Koenker statistic determines significance of coefficients, and VIF is the variance inflation factor with values $>7.5$ are indicative of redundancy. Joint Wald determines overall significance if Koenker value is significant, $A / C C$ and $R^{2}$ represent overall fit and performance

Table 2 Ordinary Least Square results for derechos

\begin{tabular}{llllllllll}
\hline & Variable & Coefficient & StdError & t-Statistic & Probability & Robust_SE & Robust_t & Robust_Pr & VIF \\
\hline Event & Intercept & -32.346 & 2.3571 & -13.7229 & $0.000000^{*}$ & 1.9912 & -16.2441 & $0.000000^{*}$ & - \\
& Elevation & 0.001 & 0.0016 & 0.6341 & 0.5260 & 0.0013 & 0.7589 & 0.4479 & 1.7764 \\
& Month & 0.407 & 0.0650 & 6.2605 & $0.000000^{*}$ & 0.0620 & 6.5668 & $0.000000^{*}$ & 1.0309 \\
& TIME_ADJ & 0.128 & 0.0258 & 4.9677 & $0.000001^{*}$ & 0.0248 & 5.1690 & $0.000001^{*}$ & 1.0270 \\
& AR_ECO_ID & 0.024 & 0.0016 & 15.1470 & $0.000000^{*}$ & 0.0015 & 15.3767 & $0.000000^{*}$ & 1.3115 \\
& Protection & 4.716 & 0.4971 & 9.4886 & $0.000000^{*}$ & 0.3091 & 15.2565 & $0.000000^{*}$ & 1.4236 \\
Magnitude & Intercept & -423.667 & 41.0222 & -10.3278 & $0.000000^{*}$ & 33.5516 & -12.6273 & $0.000000^{*}$ & - \\
& Trailer Parks & 2.423 & 0.5258 & 4.6078 & $0.000006^{*}$ & 0.5302 & 4.5697 & $0.000007^{*}$ & 1.1736 \\
& Event (Sum) & 39.873 & 0.1577 & 252.7619 & $0.000000^{*}$ & 0.1959 & 203.5371 & $0.000000^{*}$ & 1.1379 \\
& Elevation & -0.425 & 0.0281 & -15.1447 & $0.000000^{*}$ & 0.0255 & -16.6968 & $0.000000^{*}$ & 1.8430 \\
& Month & 4.531 & 1.1255 & 4.0255 & $0.000065^{*}$ & 1.0887 & 4.1618 & $0.000037^{*}$ & 1.0340 \\
& TIME_ADJ & 1.603 & 0.4466 & 3.5889 & $0.000348^{*}$ & 0.4341 & 3.6920 & $0.000237^{*}$ & 1.0294 \\
& AR_ECO_ID & 0.340 & 0.0284 & 11.9668 & $0.000000^{*}$ & 0.0272 & 12.5045 & $0.000000^{*}$ & 1.4518 \\
& Protection & 61.355 & 8.6204 & 7.1175 & $0.000000^{*}$ & 6.3061 & 9.7296 & $0.000000^{*}$ & 1.4340 \\
& & Joint Wald & Jarque-Bera & Koenker (BP) Statistic & AlCc & Adjusted R2 &
\end{tabular}

Results are initially derived from exploratory regression analysis of explanatory variables to determine variables that have had the most significant influence. Significant $p$-values $(p<0.01)$ are denoted by *, StdError is the standard deviation error, t-Statistic is the ratio between estimated and hypothesized values relative to StdError, probability and robust probability ( $\mathrm{Pr})$ are significant when $(p<0.01)$, Koenker statistic determines significance of coefficients, and VIF is the variance inflation factor with values $>7.5$ are indicative of redundancy. Joint Wald determines overall significance if Koenker value is significant, AICc and R2 represent overall fit and performance 
Table 3 Ordinary Least Squares results for hail

\begin{tabular}{llllllllll}
\hline & Variable & Coefficient & StdError & t-Statistic & Probability & Robust_SE & Robust_t & Robust_Pr & VIF \\
\hline Event & Intercept & -0.0296 & 0.2200 & -0.1346 & 0.8929 & 0.2050 & -0.1444 & 0.8852 & - \\
& SUM_MAG & 0.8729 & 0.0009 & 1023.3266 & $0.000000^{*}$ & 0.0016 & 561.5929 & $0.000000^{*}$ & 1.0212 \\
& MO & 0.0409 & 0.0076 & 5.3547 & $0.000000^{*}$ & 0.0078 & 5.2433 & $0.000000^{*}$ & 1.0241 \\
& HAIL_TIM_2 & -0.0082 & 0.0033 & -2.4808 & $0.013107^{*}$ & 0.0033 & -2.4926 & $0.012680^{*}$ & 1.0196 \\
& ELEVATION & 0.0015 & 0.0001 & 10.8536 & $0.000000^{*}$ & 0.0001 & 12.5462 & $0.000000^{*}$ & 1.2704 \\
& AR_ECO_ID & -0.0004 & 0.0002 & -2.1620 & $0.030620^{*}$ & 0.0002 & -2.2770 & $0.022785^{*}$ & 1.2861 \\
\multirow{3}{*}{ Magnitude } & Intercept & -0.2115 & 0.2501 & -0.8456 & 0.3978 & 0.2248 & -0.9406 & 0.3469 & - \\
& SUM_EVENT & 1.1281 & 0.0011 & 1023.3266 & $0.000000^{*}$ & 0.0021 & 533.7691 & $0.000000^{*}$ & 1.0215 \\
& MO & -0.0422 & 0.0087 & -4.8542 & $0.000002^{*}$ & 0.0088 & -4.7753 & $0.000003^{*}$ & 1.0244 \\
& HAIL_TIM_2 & 0.0115 & 0.0037 & 3.0678 & $0.002173^{*}$ & 0.0037 & 3.0856 & $0.002049^{*}$ & 1.0194 \\
& ELEVATION & -0.0018 & 0.0002 & -11.2164 & $0.000000^{*}$ & 0.0001 & -12.8938 & $0.000000^{*}$ & 1.2698 \\
& AR_ECO_ID & 0.0008 & 0.0002 & 4.1671 & $0.000037^{*}$ & 0.0002 & 4.5625 & $0.000007^{*}$ & 1.2851 \\
& & & Joint Wald & Jarque-Bera & Koenker (BP) Statistic & AlCc & Adjusted R2 &
\end{tabular}

OLS analysis shows very low VIF values meaning low model redundancy and all explanatory variables prove to be statistically significant denoted by asterisk. Significant $p$-values $(p<0.01)$ are denoted by *, StdError is the standard deviation error, t-Statistic is the ratio between estimated and hypothesized values relative to StdError, probability and robust probability (Pr) are significant when $(p<0.01)$, Koenker statistic determines significance of coefficients, and VIF is the variance inflation factor with values $>7.5$ are indicative of redundancy. Joint Wald determines overall significance if Koenker value is significant, AICc and R2 represent overall fit and performance

std for over-prediction/under-prediction of the final model. These results are reliable being within the accepted \pm 2 std of error.

Lyza and Knupp (2013) noted four common modes of behavior with tornadoes that can help explain the high magnitude and frequency in central Arkansas along with the protected zones in the Ouachita and Boston Mountain region immediately north of the Arkansas River Valley. Mode 1: where tornadic strength deteriorates on the up slopes, proved to be consistent in the findings of Selvam et al. (2014) with the Mayflower Tornado. Mode 2: tornado whirl pattern intensifies on plateaus but weakens as the

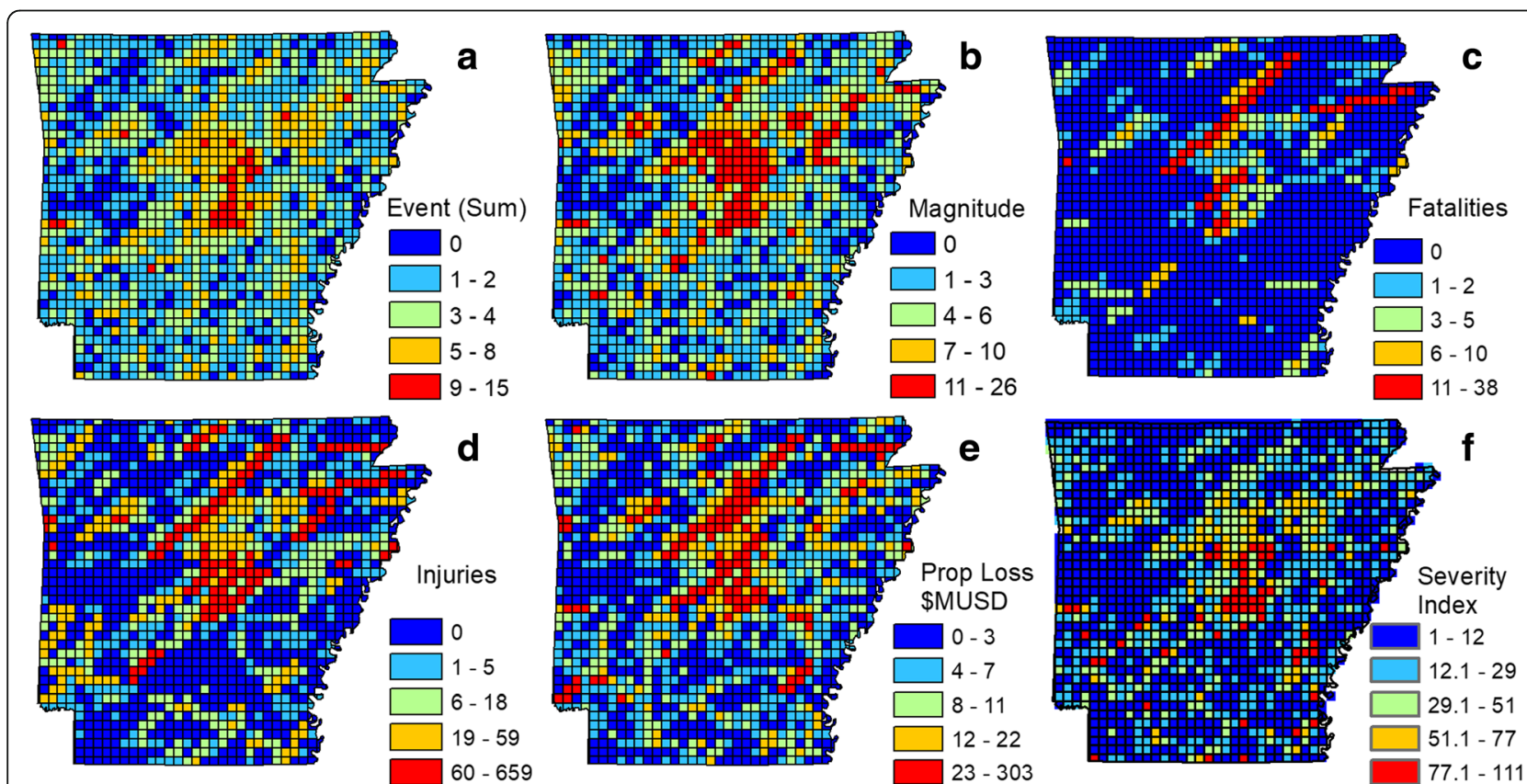

Fig. 6 Tornado Damage (grid cell $=10 \times 10 \mathrm{~km}$ ): a Sum of all events (frequency) b Sum of EF tornado magnitudes $\mathbf{c}$ Fatalities (some grids approach 40 fatalities over the 60-yr study period) $\mathbf{d}$ Injuries (many grids show 650+ injuries over the study period) e Property damage follows the same path of the largest magnitude tornadic events $\mathbf{f}$ Tornado severity index 

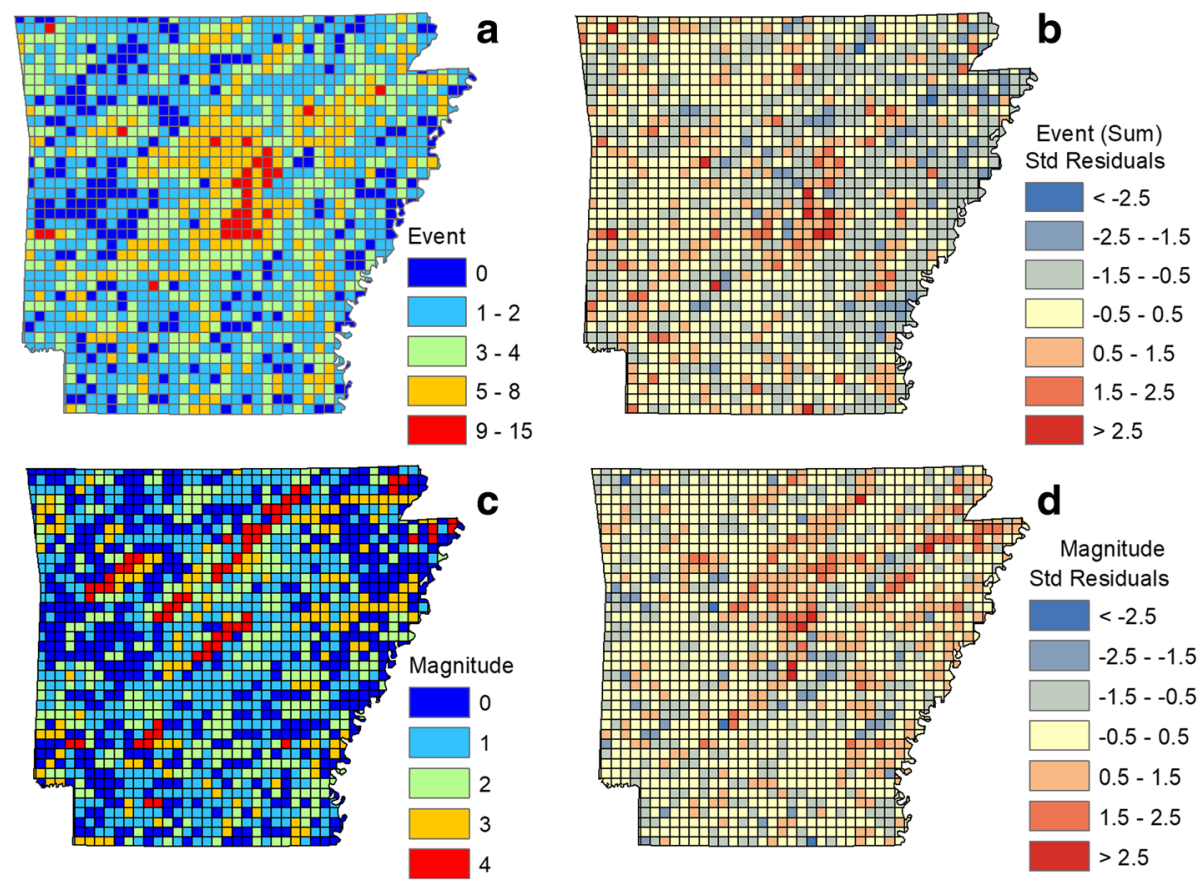

Fig. 7 Ordinary Least Squares (OLS) regression analysis for the explanatory variables influencing tornados (grid cell $=10 \times 10 \mathrm{~km}$ ): $\mathbf{a}$ frequency $\mathbf{b}$ OLS are dominant within 1 standard deviation (Std) for the explanatory variable residuals c magnitude $\mathbf{d}$ OLS show low $(<1)$ standard deviation for residuals signifying robustness of model prediction

whirl moves of the plateau, potentially helping to explain the central Boston Mountain low severity zone. Mode 3: tornado tracts tend to follow valleys like a hallway, once again related to the Ouachita Mountains which are systematically folded long linear ridges and valleys helping funnel wind driven weather patterns from west to east into Little Rock. Mode 4: tornadoes have a tendency to trace the edges of ridges and plateaus. That has been also observed by Selvam et al. (2014) in Mayflower and can explain the strong tendency of EF-3 and EF-4 tornadoes to trend along the eastern boundary that the Ouachita Mountains makes with the Mississippi Embayment (refer back to Fig. 1 for physiographic provinces of Arkansas).

Derechos are the second most destructive hazardous weather events in Arkansas. Investigation of spatial patterns has identified the highest magnitude cluster in northwest Arkansas. This is critical because NWA has the second highest population in the state, 300,000+ residents as well as a large commuter group working in the metropolitan area, and the region is an economic hub for the USA. Property damage and crop loss may reach into \$17.4 million dollars for single grid cells (Fig. 8). Fatalities are infrequent but do occur with these events, however injuries are more common (Fig. 4) due to the violent nature (50-100 knots) and the abruptness of these events, which just seem to come out of nowhere. OLS conducted on derecho events and magnitude (Fig. 9), using EVs of time, month, elevation, topographic protection, sum of magnitudes, sum of events, mobile home concentration, and eco-region, has produced robust and statistically significant $(p<0.01)$ coefficients, except for elevation, which is not found to be a good EV for event frequency although patterns are observed at specific elevations previously mentioned. Outside of these tight elevation windows, random patterns are observed. Table 2 shows the OLS outputs for the regression analysis. The $R^{2}$ of 0.9857 has a strong indication that the EVs chosen are sufficient at explaining the dependent variables. OLS shows that all explanatory inputs have VIF values below 2, where VIF values $>7.5$ indicate redundancy of EVs.

Hail is found to be the least destructive and the least problematic of the three weather types being considered in Arkansas. Hail is often associated with tornadoes and derechos but has occurred in localized incidents across the state, as shown in Fig. 10. A line of destruction amounting to $\$ 7$ million dollars' worth of crop loss and $\$ 85$ million dollars in property damage can be traced directly east of Little Rock, Arkansas (Fig. 10e). No fatality due to hail events has occurred during the study period and injuries are minimal (Fig. 4). Figure 10 displays OLS results for event frequency and magnitude from inputs of EVs: time, month, elevation, topographic protection, sum of magnitudes, sum of events, eco-region. These EVs produced statistically significant coefficients with $p$-values 

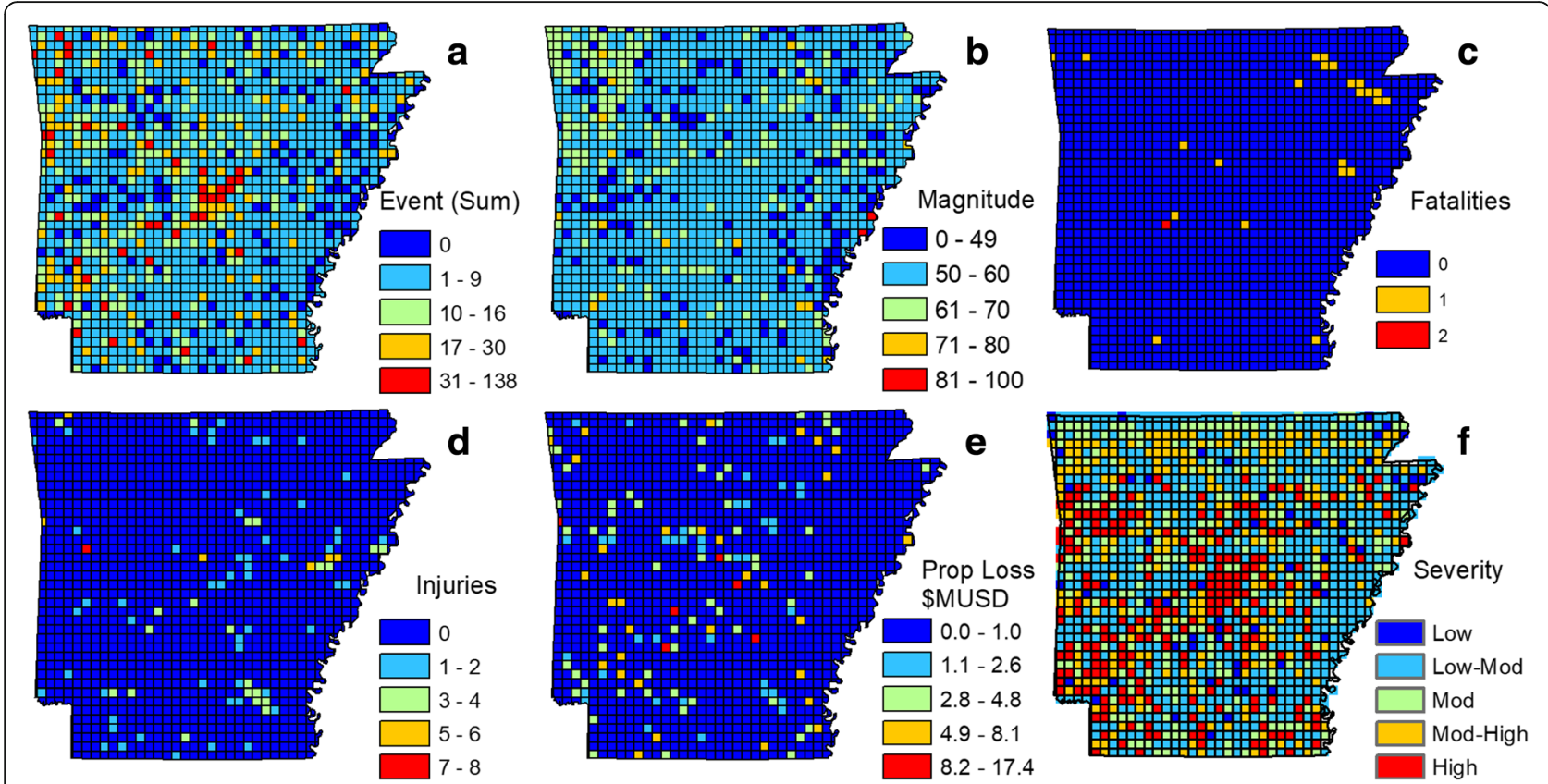

Fig. 8 Derecho damage (grid cell $=10 \times 10 \mathrm{~km}$ ): a Sum of all events $\mathbf{b}$ Derecho magnitude (0-100 knots) c Fatalities $\mathbf{d}$ Injuries e Property damage (structures or vehicles) $\mathbf{f}$ Derecho severity index

$<0.01$, implying a robust model for explanation of historical hail patterns. OLS outputs in Table 3 provide ancillary validation for $R^{2}$ values of 0.84911 , indicating the respective EVs chosen are sufficient at explaining $~ 85 \%$ of dependent variables. Applying EVs (time, month, elevation, topographic protection, sum of magnitudes, sum of events, concentration of mobile homes) to OLS regression analysis for events and magnitude (Fig. 11) shows that these EVs perform well at explaining most of the events but as with tornadoes and derechos still struggled at fully
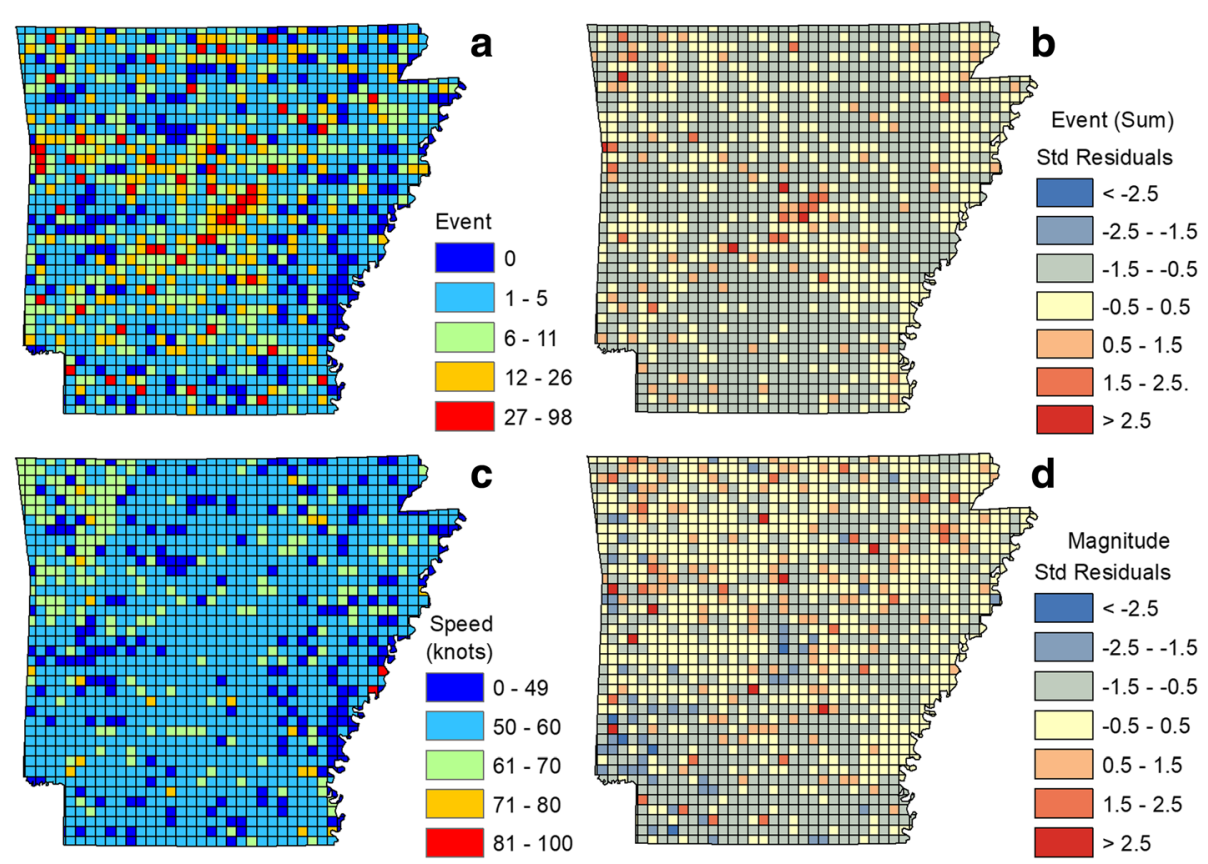

Fig. 9 Ordinary Least Squares (OLS) regression analysis for the explanatory variables influencing derechos (grid cell = $10 \times 10 \mathrm{~km}$ ): a frequency b OLS are dominant within 1 standard deviation (Std) for the explanatory variable residuals c speed $\mathbf{d}$ OLS show low $(<1)$ standard deviation for residuals signifying robustness of model prediction 

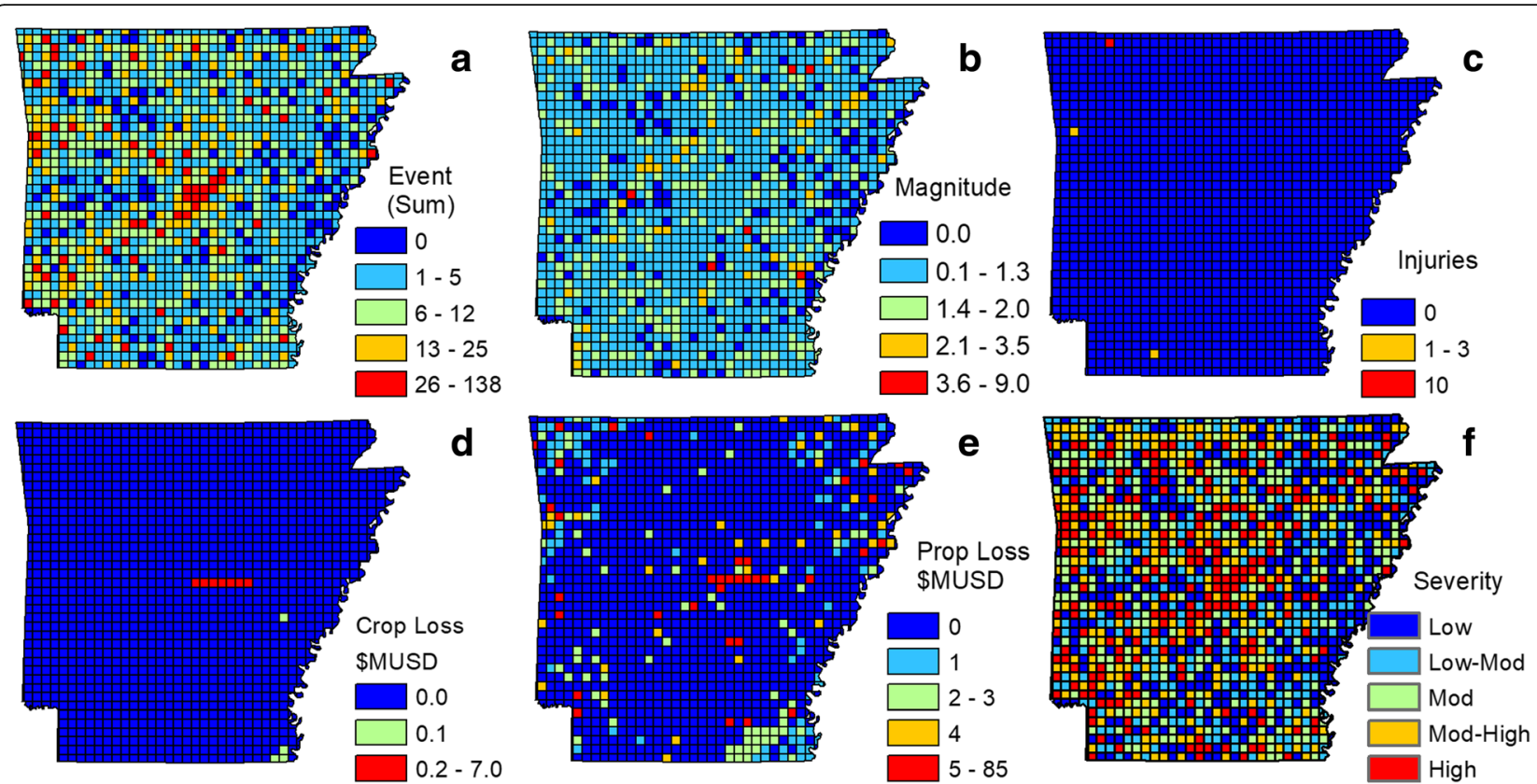

Fig. 10 Hail Damage (grid cell=10×10 km): a Sum of all events $\mathbf{b}$ Magnitudes for hail ranging between 0.1 and 9.0 (pea-size to grapefruit respectively) c Fatalities $\mathbf{d}$ Injuries sustained during hail events e Property losses including structures and vehicles $\mathbf{f}$. Hail severity index. No fatalities have been directly attributed to hail during the study period, so choropleth has been omitted and instead crop loss has been represented instead because of the significant damage

explaining the highest frequency and magnitude of events found in central Arkansas. This being said, even the outliers fall within \pm 2 stds of error.

Our summed statewide severity product (Fig. 12) is consistent with local outputs from previous case studies by ADEM and FEMA (FEMA 2002) and clearly identifies various zones of severity across the entire state. This can help the state and other governmental agencies focus on the identified vulnerable spots to build public shelters and offer residential shelter grants. An interesting pattern of low severity found in the central Ouachita and Boston Mountains is consistent with topographic terrain protection theories proposed by previous researchers (e.g. Fujita 1989; Lapenta et al. 2005; Bosart et al. 2006; Gaffin 2012; Lewellen 2012; Lyza and Knupp 2013). These observed patterns are consistent with aforementioned explanations for transitional zones of moderate severity as well as pockets of highest severity where topographic corridors funnel westerly storms along the eastern front of the Ouachita's and the second pattern through the Arkansas River Valley toward Little Rock.

The summed severity map shows a strong correlation between high severity and major population centers. A similar observation has been documented by Kellner and Niyogi (2013) where they spatially calculated touchdown points in Indiana to find that $61 \%$ of EF0-EF5 tornadoes touchdown within $1-3 \mathrm{~km}$ of urban landuse area bordering landcover classified as forest. Areas surrounding Little Rock in central Arkansas, which have had the highest incidence of tornadic and derecho activity, suffer from not only topographic terrain influence in the Ouachita Mountains to the immediate west, but also a wind corridor effect through the Arkansas River Valley, as well as flat topography with land surface heterogeneity.

\section{Conclusions}

Complacency is a deadly human tendency that overcomes residents, especially when weather-related disasters have not occurred in recent years. Severe weather events sometimes occur simultaneously during the largest and most powerful storm system such as the example of the January 22, 2012, which impacted the entire Arkansas Delta. Robust and viable statistics can help re-enforce the imperative need for storm shelters and higher building codes to better prepare for such extreme weather events. Better understanding of severe weather patterns and preferential tendency for storms to frequent certain cities, regions, or trajectories is the first step in mitigating risk by minimizing exposure and vulnerability in these highest severity regions.

Analysis of the severe weather events from 1955 to 2015 reveals a very strong positive correlation with time of the day, in association with the three weather types under consideration. The extreme weather events are found to most likely occur between 2:00 and 10:00 pm local time. This is 

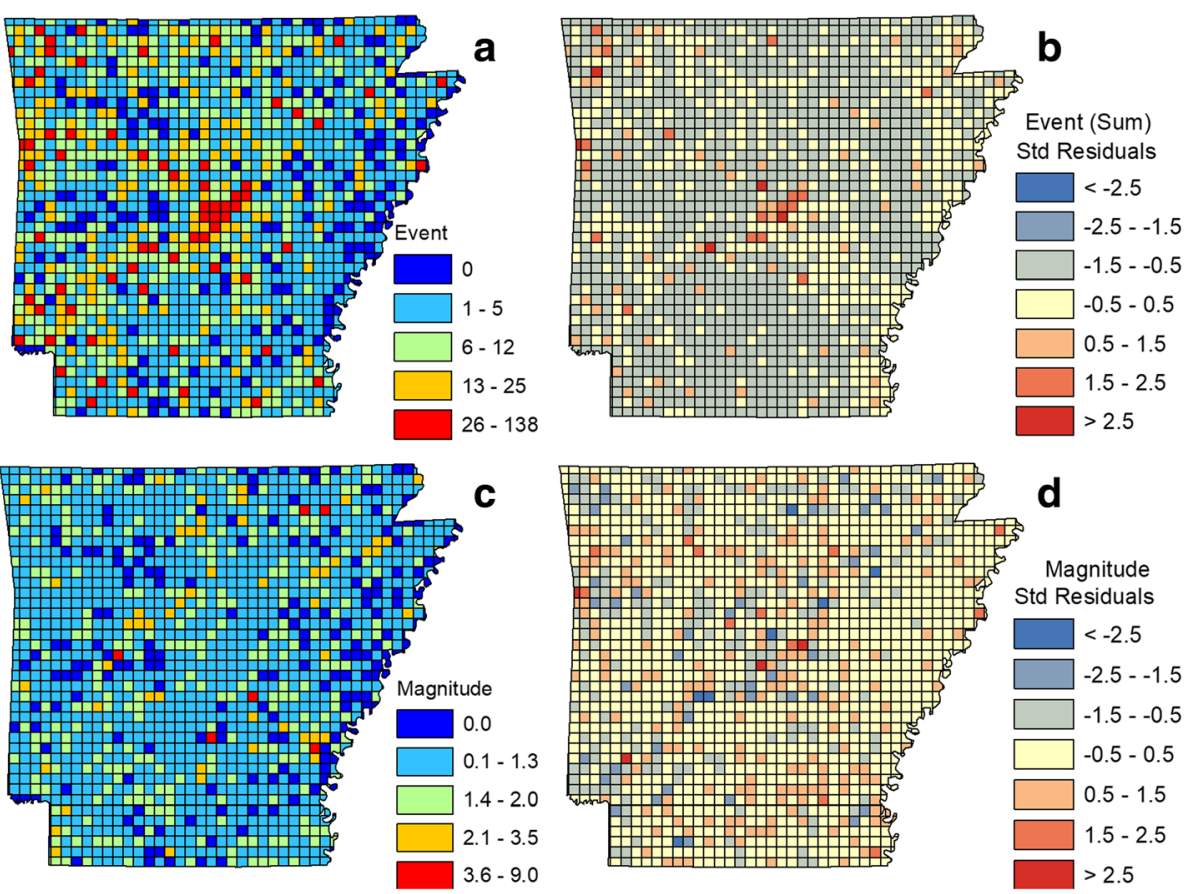

Fig. 11 Ordinary Least Squares (OLS) regression analysis for the explanatory variables influencing hail (grid cell = $10 \times 10 \mathrm{~km}$ ): a frequency $\mathbf{b}$ OLS are dominant within 1 standard deviation (Std) for the explanatory variable residuals $\mathbf{c}$ magnitude $\mathbf{d}$ OLS show low $(<1)$ standard deviation for residuals signifying robustness of model prediction

of vital importance because line-of-sight is reduced to near zero visibility at night, thus residents in most of fall and winter months must rely on National Weather Service warnings. Raising public awareness to the frequency and likelihood of such geoenvironmental risks occurring in evening hours may help bolster residents taking advantage

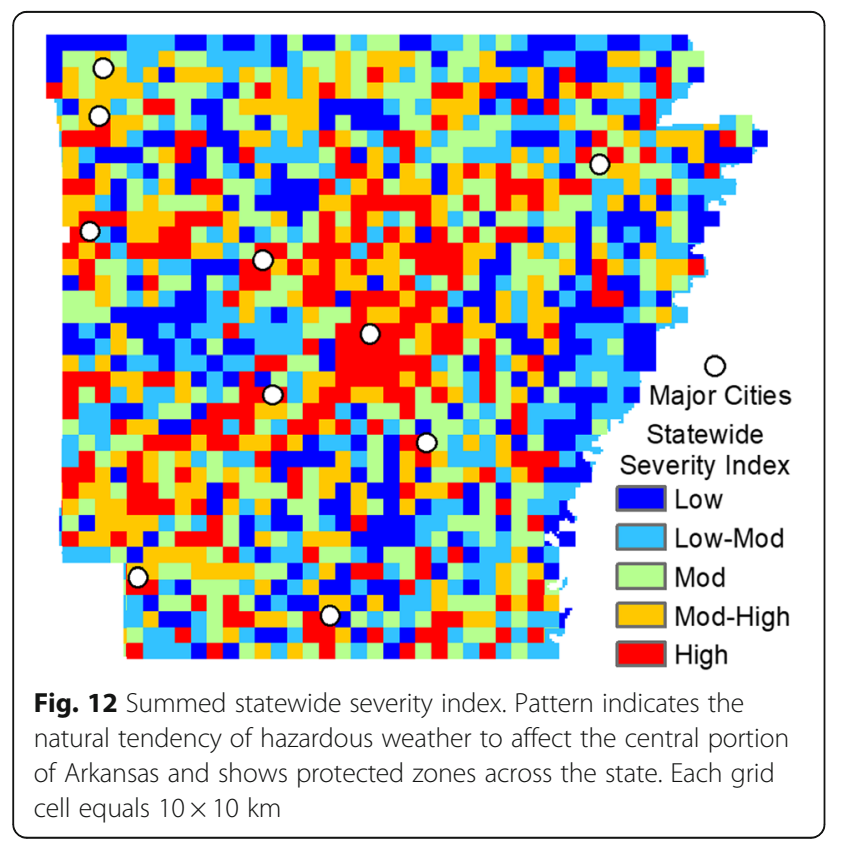

of FEMA funding for building residential shelters in rural areas and community shelters in more urban settings.

Our findings in this study provide statistically robust evidence for variables that respond to Lewellen's (2012) question regarding whether it is statistically possible to prove that topography might influence regional weather patterns. Along with topographic influence, this study also found that other physiographic features such as elevation, physiographic provincial sub regions, and most importantly the windward protection afforded to leeward sides of physiographic features are statistically significant $\mathrm{EV}$ in predicting severe weather patterns.

The explanatory variables of time of day, month, elevation, physiographic region (subclass), topographic protection, elevation, and concentration of trailer parks are not only effective at forecasting severe weather patterns but also have been found to be statistically robust through OLS regression analysis. Susceptibility models based on these variables may provide substantially higher precision for spatio-temporal patterns, which in turn can be used by ADEM and FEMA as well as other first responding agencies, and residents to better access risk beyond the broad umbrella of previous county-wide assessments. The developed methodology can be applied to a broad spectrum of severe weather around the globe to improve hazard mitigation and help with preparedness for geoenvironmental disasters. 


\section{Acknowledgements}

This study has been conducted using the research facilities in the InSAR Lab, which is part of the Center for Advanced Spatial Technologies and the Department of Geosciences at the University of Arkansas. Thanks are due to the three anonymous reviewers and the Editor, Fawu Wang, for their thorough reviews, comments, and suggestions.

\section{Funding}

NASA EPSCoR RID, grant \#24203116UAF, awarded to Mohamed H. Aly.

\section{Availability of data and materials}

All weather and mobile home concentration data are publicly available from NOAA/NWS Geodata as part of the Storm Prediction Center's SVRGIS. Arkansas GIS data are publicly available from www.spc.noaa.gov/gis/svrgis/ and https://gis.arkansas.gov.

\section{Authors' contributions}

Both authors developed the research methodology, wrote the manuscript, and improved the revised version of the paper. Both authors read and approved the final manuscript.

\section{Competing interests}

The authors declare that they have no competing interests.

\section{Publisher's Note}

Springer Nature remains neutral with regard to jurisdictional claims in published maps and institutional affiliations.

\section{Received: 28 December 2017 Accepted: 12 March 2018}

\section{Published online: 27 March 2018}

\section{References}

Ahmed N, Selvam RP (2015a) Tornado-Hill interaction: Damage and sheltering observations. Inter. J. App. Earth Observ. and Geoinfo. Str.

Ahmed N, Selvam RP (2015b) Topography effects on tornado path deviation. University of Arkansas Computer Mechanics lab Internal Paper, 1-31.

Ahmed N, and Selvam RP (2015c) Ridge effects on tornado path deviation. Int. J. Civil Str. Eng. Res 3 (1): 273-294.

Ahmed, N. 2016 Field observations and computer modeling of tornado-terrain interaction and its effects on tornado damage and path. Thesis, University of Arkansas.

Akaike, H. 1973. Information theory and an extension of the maximum likelihood principle, in Petrov, B.N.; Csáki, F., 2nd International Symposium on Information Theory, Tsahkadsor, Armenia, USSR, September 2-8, 1971, Budapest. Akadémiai Kiadó, 267-281.

Akaike, H. 1974. A new look at the statistical model identification. IEEE Transactions on Automatic Control 19 (6): 716-723. https://doi.org/10.1109/TAC.1974.1100705.

Akaike, H. 2011. Akaike's information criterion. Int. Encyc. Stat. Sci 2: 1-25. https://doi.org/10.1007/978-3-642-04898-2_110.

Amemiya, T. 1985. Advanced economics. Massachusetts: Harvard University Press.

Arkansas Farm Bureau (2017) Agriculture facts, http://www.arfb.com/pages/ education/ag-facts/.Accessed 22 November 2017.

Arkansas State University (2016) The Arkansas State University system 2015-2016 factbook, Office of Institutional Research and Planning. 1-91.

Belsley, D.A. 1984. Demeaning conditioning diagnostics through centering. The American Statistician 38: 73-82. https://doi.org/10.1080/00031305.1984.10483169.

Belsley, D.A., E. Kuh, and R.E. Welsch. 1980. Regression diagnostics: Identifying influential data and sources of collinearity. New York: Wiley.

Bosart, L.F., A. Seimon, K.D. LaPenta, and M.J. Dickinson. 2006. Supercell tornadogenesis over complex terrain: The Great Barrington, Massachusetts, tornado on 29 may 1995. Wea. Forecasting 21: 897-922.

Bradford, M. 1999. Historical roots of modern tornado forecasts and warnings. Wea. Forecasting 14: 484-491. https://doi.org/10.1175/1520-0434(1999)014<0484: HROMTF> 2.0.CO:2.

Bradford, M. 2001. Scanning the skies: A history of tornado forecasting, 220. University of Oklahoma Press.

Breusch, T.S., and A.R. Pagan. 1979. A simple test for heteroscedasticity and random coefficient variation. Econometrica 47: 1287-1294. https://doi.org/10. 2307/1911963.
Brewer, C.A., and L. Pickle. 2002. Evaluation of methods for classifying epidemiological data on choropleth maps in series. Ann. Assoc. Am. Geog 92: 662-681.

Burnham, K.P., and D.R. Anderson. 2002. Model selection and multimodel inference: A practical information-theoretic approach. 2nd ed. New York: Springer-Verlag.

Coleman, T.A., K.R. Knupp, J. Spann, J.B. Elliott, and B.E. Peters. 2011. The history (and future) of tornado warning dissemination in the United States. Am. Meteor. Soc 567-582. https://doi.org/10.1175/2010BAMS3062.1.

Crichton, D. 1999. The risk triangle, natural disaster management. Ingleton, J., (ed), Tudor rose London.

Cromley, R.G. 1996. A comparison of optimal classification strategies for choroplethic displays of spatially aggregated data. Inter. J. Geog. Infor. Sci 10 (4): 405-424. https://doi.org/10.1080/02693799608902087.

Edwards R (2017) The online tornado FAQ: Frequently asked questions about tornadoes. National Oceanic and Atmospheric Administration Storm Prevention Center. www.spc.ncep.noaa.gov/faq/tornado. Accessed 27 October 2017.

ESRI (2016) ArcGIS10.4.1 desktop help. http://resources.arcgis.com/en/help/. Accessed 15 June 2017

FEMA (2002) Community wind shelters: background and research. http://www.fema gov/plan/prevent/bestpractices/casestudies.shtm. Accessed 12 Oct 2017.

FEMA (2008) Arkansas' tornado shelter initiative for residences and schools: Mitigation case studies.

Forbes, G.S., and H.B. Bluestein. 2001. Tornadoes, tornadic thunderstorms, and photogrammetry: A review of the contributions by T. T. Fujita. Bull. Amer. Meteor. Soc 82 (1): 73-96. https://doi.org/10.1175/1520-0477.

Forbes, G.S., M.L. Pearce, T.E. Dunham, and R.H. Grumm. 1998. Downbursts and gustnadoes from mini-bow echoes and affiliated mesoscale cyclones over Central Pennsylvania. Preprints. In 16th Conf. On weather analysis and forecasting, Phoenix, AZ, Amer, 295-297. Meteor. Soc.

Fortune. 2017. The global 500: The world's largest companies. New York City: Time.

Frame, J., and P. Markowski. 2006. The interaction of simulated squall lines with idealized mountain ridges. Mon. Wea. Rev 134: 1919-1941. https://doi.org/10. 1175/MWR3157.1.

Fujita TT (1971) Proposed characterization of tornadoes and hurricanes by area and intensity. SMRP research paper 91, University of Chicago, 42 pp.

Fujita, TT. 1989. The Teton-Yellowstone tornado of 21 July 1987. Mon. Wea. Rev., 117(9):1913-1940. https://doi.org/10.1175/1520-0493(1989)117<1913: TTYTOJ>2.0.CO;2

Gaffin, D.M. 2012. The influence of terrain during the 27 April 2011 super tornado outbreak and 5 July 2012 derecho around the great Smoky Mountains National Park. Preprints, 26th conference on severe local storms, Nashville, TN. Amer. Meteor. Soc.

Galway, J.G. 1985. J.P. Finley: The first severe storms forecaster. Bull. Amer. Meteor. Soc 66: 1389-1395. https://doi.org/10.1175/1520-0477(1985)066<1389: JFTFSS $>2.0 . C O ; 2$.

Gosset, W.S. 1908. The probable error of a mean. Biometrika 6 (1): 1-25.

Jarque, C.M., and A.K. Bera. 1980. Efficient tests for normality, homoscedasticity and serial independence of regression residuals. Economics Letters 6 (3): 255-259. https://doi.org/10.1016/0165-1765(80)90024-5.

Jarque, C.M., and A.K. Bera. 1981. Efficient tests for normality, homoscedasticity and serial independence of regression residuals: Monte Carlo evidence. Econ. Let 7 (4): 313-318. https://doi.org/10.1016/0165-1765(81)90035-5.

Jarque, C.M., and A.K. Bera. 1987. A test for normality of observations and regression residuals. Inter. Stat. Rev 55 (2): 163-172.

Karstens, C.D., W.A. Gallus, B.D. Lee, and C.A. Finley. 2013. Analysis of tornadoinduced tree fall using aerial photography from the Joplin, Missouri, and Tuscaloosa-Birmingham, Alabama, tornadoes of 2011. J. Appl. Meteor. Climato/ 52: 1049-1068. https://doi.org/10.1175/JAMC-D_12_0206.1.

Kellner, O., and D. Niyogi. 2013. Land-surface heterogeneity signature in tornado climatology: An illustrative analysis over Indiana 1950-2012. Earth Inter.,18(10): 1-32. https://doi.org/10.1175/2013El000548.1.

Koenker, R. 1981. A note on studentizing a test for heteroscedasticity. Journal of Econometrics 17 (1): 107-112. https://doi.org/10.1016/0304-4076(81)90062-2.

Konishi, S., and G. Kitagawa. 2008. Information criteria and statistical modeling. New York: Springer.

Kuligowski, E.D., F.T. Lombardo, L.T. Phan, M.L. Levitan, and D.P. Jorgensen. 2014. Final report, National Institute of Standards and Technology (NIST) technical investigation of the may 22, 2011, tornado in Joplin, Missouri. Nat. Const. Safety team act rep. NIST NCSTAR 3: 1-428. https://doi.org/10.6028/NIST. NCSTAR.3. 
LaPenta, K.D., L.F. Bosart, T.J. Galarneau, and M.J. Dickinson. 2005. A multiscale examination of the 31 may 1998 Mechanicville, New York, tornado, weather and forecasting. Am. Meteor. Soc 20 (1): 494-516. https://doi.org/10.1175/NAD875.1. Lewellen, D.C. 2012. Effects of topography on tornado dynamics: a simulation study. 26th Conference on Severe Local Storms (5-8 November 2012) Nashville, TN, am. Meteor. Soc. https://ams.confex.com/ams/26SLS/ webprogram/Paper211460.html Accessed 6 Nov 2017.

Lyza AW, Knupp KR (2013) An observational analysis of potential terrain influences on tornado behavior. Severe Weather Institute and Radar \& Lightening Laboratories (SWIRLL), University of Alabama, Huntsville. Internal Paper. 1-7.

Markowski, P.M., and N. Dotzek. 2011. A numerical study of the effects of orography on supercells. J. Atmos. Res. 100: 457-478. https://doi.org/10.1016/ j.atmosres.2010.12.027.

National Climatic Data Center (2013) U.S. tornado climatology. https://www.ncdc. noaa.gov/climate-information/extreme-events/us-tornado-climatology. Accessed 22 Nov 2017.

NOAA (2017a) Converting traditional hail size descriptions, storm prediction center, http://www.spc.noaa.gov/misc/tables/hailsize.htm. Accessed 22 Nov 22, 2017.

NOAA (2017b) SPC tornado, hail, and wind database format specification (for .cSV output). http://www.spc.noaa.gov/wcm/\#data. Accessed 15 Sept 2017.

O'Brien, R.M. 2007. A caution in regarding rules of thumb for variance inflation factors. Quality \& Quantity 41: 673-690. https://doi.org/10.1007/s11135-0069018-6.

Safeguard (2009) Safeguard storm shelters - Fujita Scale. http://www. safeguardshelters.com/fujitascale.php. Accessed 21 Oct 2017.

Selvam RP, Ahmed NS, Yousof MA, Strasser M, Costa A (2015) RAPID: Documentation of tornado track of mayflower tornado in hilly terrain.

Selvam RP, Ahmed NS, Yousof MA, Strasser M, Ragan Q (2014) Study of tornado terrain interaction from damage documentation of April 27, 2014 mayflower, AR tornado. Department of Civil Engineering, University of Arkansas, Fayetteville, AR 72701.

Steel, R.D.G., and J.H. Torrie. 1960. Principles and procedures of statistics with special reference to the biological sciences. McGraw Hill.

Sun, M., D.W. Wong, and B.J. Kronenfeld. 2015. A classification method for choropleth maps incorporating data reliability information. The Professional Geographer 67 (1): 72-83. https://doi.org/10.1080/00330124.2014.888627.

Tobler, WR. 1970. A Computer Movie Simulating Urban Growth in the Detroit Region. Econ. Geogr. 46:234. http://www.jstor.org/stable/143141

United States Census Bureau. 2016. Annual estimates of the resident population: April 1, 2010 to July 1, 2016. U.S.: Census Bureau Population Division https:// factfinder.census.gov. Accessed 22 Nov 2017.

University of Arkansas (2017) Fall 2017 11th day enrollment report, Office of Institutional Research and Assessment, https://oir.uark.edu/students/ enrollment-report.php, Accessed 22 Nov 2017.

Xiao, N., C.A. Calder, and M.P. Armstrong. 2007. Assessing the effect of attribute uncertainty on the robustness of choropleth map classification. Int. J. Geog. Inf. Sci 21 (2): 121-144. https://doi.org/10.1080/13658810600894307.

\section{Submit your manuscript to a SpringerOpen ${ }^{\circ}$ journal and benefit from:}

- Convenient online submission

- Rigorous peer review

- Open access: articles freely available online

- High visibility within the field

- Retaining the copyright to your article

Submit your next manuscript at $>$ springeropen.com 